\title{
Beauty Mask: Market and Environment
}

\author{
Morganti $\mathrm{P}^{1, *}$, Gianluca Morganti ${ }^{2}$, Hong-Duo Chen $^{3}$, and Gagliardini $\mathrm{A}^{4}$ \\ ${ }^{1}$ Campania University, L Vanvitelli, Dermatol Unit, Naples, Italy \\ ${ }^{2}$ ISCD Nanoscience Research Center, Rome, Italy \\ ${ }^{3}$ Dermatology Department, China Medical University, Shenyang, China \\ ${ }^{4}$ Atertek, R\&D Unit, Pescara, Italy
}

*Corresponding author: Morganti P, Campania University, L Vanvitelli, Dermatol Unit, Naples, Italy, Tel: 390815666833; E-mail: pierfrancesco.morganti@iscd.it

Received: 14 Sep, 2019 | Accepted: 20 Sep, 2019 | Published: 27 Sep, 2019

Citation: Morganti P, Morganti G, Chen HD, Gagliardini A (2019) Beauty Mask: Market and Environment. J Clin Cosmet Dermatol 3(2): dx.doi.org/10.16966/2576-2826.141

Copyright: (C) 2019 Morganti P, et al. This is an open-access article distributed under the terms of the Creative Commons Attribution License, which permits unrestricted use, distribution, and reproduction in any medium, provided the original author and source are credited.

\begin{abstract}
Beauty Masks represent a niche of the cosmetic market that has shown a booming growth in the last years. This category of cosmetics is formulated as a cream, gel, lotion, serum, sheet, etc, containing active ingredients useful to quickly improve the skin face appearance. In particular, the sheet masks are generally made by non-woven tissues imbibed of active ingredients with the main function of hydrate the skin, slowing down wrinkles, fine lines and aged spots. The consumer request is prevalently oriented vs. products made possibly by natural ingredients skin-friendly and environmentallyfriendly. This paper shows the possibility to realize non-woven tissues which, made by fibers, of natural oligosaccharides and chitoolisaccharides, such as chitin and lignin able to bind and release active ingredients, may be used as smart Beauty Masks. Differently from the actual in-commerce sheets, these innovative cosmetics, made by the use of waste materials, are free of preservatives, emulsifiers, colors, fragrances, chemicals and globally biodegradable.
\end{abstract}

Keywords: Oligosaccharides; Chitin nanofibrils; Nanolignin; Non-woven tissues; Face beauty masks; Prestige care market; Sustainability

\section{Introduction}

Asia is actually the dominant player in global skincare sales, amassing $51 \%$ of the world's value sales and $6 \%$ of compound annual growth rate (CAGR) between 2012-2017, according to the data presented recently by Euromonitor [1]. Among the products, "facial" is the more used family of skincare treatments (i.e., for the "face"), including products such as creams, lotions, peels and masks, performed normally in beauty salons and in spa (Figure 1).

About the facial mask, the consumers of Asia-Pacific (ASEAN) are the biggest users and innovators of this cosmetic category, with around $63 \%$ of the total sale. It is, in fact, a specific product that has been included as part of their regular skincare routine regimes. In this niche-market, EU makes up 16\%, while USA is setting $8 \%$ only [2], also if the customers of these countries are beginning to use the Facial Masks as a routine skincare basis.

However, the consume of this specialized product is rapidly expanding, so that worldwide it became the fastest growing segment in personal care regimen. Consequently, the facial mask selling is booming with a CAGR of around $10 \%$, while skincare market currently has growth at around 5.2\% from the year 2000 to 2019 [3].

But how is it made and which is the Facial mask use?
The mask, formulated as cream, ointment, lotion, serum, or sheet, is just a vehicle that delivers "actives" to the skin with the main scope to quickly improve its appearance and quality. This category of cosmetics, packed in different ways and by different materials, is selected according to skin type, so that for example clay and mud masks suit oily skin, while cream-based masks seems to work best on dry skin.

The sheet mask, made generally by tissues, is another primary segment introduced in the market with different innovation as, for example, "one-minute face mask", having the main function to hydrate and calm the skin quickly and easily. It comprises of different types of fabric which includes cotton, non-woven, hydrogel, bio-cellulose and others. However, being a key target category, the sheet mask-niche represents the most challenging cosmetic product in an open market that has to sustain continually the consumer interest by new products development, new packagings, innovative positioning claims, and ingredients. This market, in fact, has to match different facial mask formats and formulations, able to deliver maximum efficacy [4,5]. At this purpose, the origin of ingredients used and the maintenance of environmental surroundings' safeguarding became highly shaped by consumer choice. Thus, the consumer- manufacturer cooperation has enforced a sense of mutuality between all the supply chain partners to diminish the impact of carbon footprint. At this purpose, Eco-label 


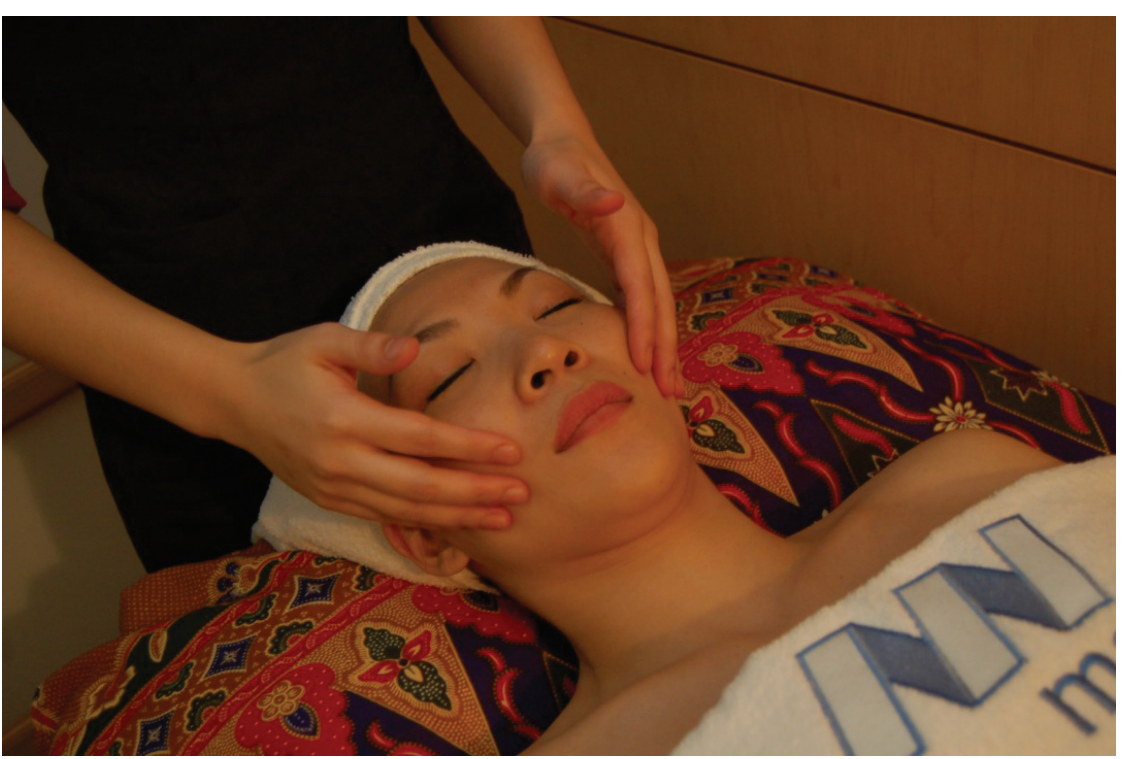

Figure 1: Face treatment into the spa (By courtesy of Imprees Esteem, Malaysia).

has been discussed as an effective tool for promoting a sustainable development and environmentally-friendly product information from the producer to the consumer, who day by day wishes to protect her/himself from the increasing air pollution (Figure 2).

Rinsing aging population, and growing trend in personal beauty enhancer' products are, therefore globally booming the sheet face masks market. In addition, increasing skincare awareness among young generation, specifically in Asia-Pacific region, together with the rise in male grooming products, are driving the growth of this market also. Consumers, in fact, rather than look youngest want to simply look good for their actual age. The real interest is to appear "healthy, happy and well aged" in a clean Planet. As a consequence, it is mandatory to control the safeness and effectiveness of these new products, verifying also the impact they could have on health, market and environment.

\section{The Market}

Facial mask represents an important and increasing segment of the prestige beauty care market, connected with educated smart consumers tacking for one minute product, possibly characterized for its safeness and effectiveness, [1]. Its global market value evaluated US\$ 27.12 billion in 2015, is expected to grow at a CAGR between $6.46 \%$ to $8.97 \%$, reaching the value of US $\$ 37.80$ billion by $2020[5,6]$. This interesting growth is due to the specific characteristics of the adopted formulations, able to influence the skin well-being.

About the regions and as previously reported, Asia consumers are known to be the biggest users of facial masks, being included as part of their regular skincare routine treatments. According to Mintel' data [2], the Asia-Pacific area is identified at present as among the world's largest facial care markets, and in 2017, the facial mask segment has registered a retail value of US\$ 15.8 Billion in China and US\$ 13.5 Billion in Japan. South Korea is already one of the top three markets with US\$ 6.6 billion.

The dominant player for the facial mask, therefore, remains Asia, with an amazing $63 \%$ of the global world's value sales, $28 \%$ of which in China, $12 \%$ in Taiwan 10\% in South Korea, 7\% in Hong Kong, and $6 \%$ in Japan. It seems, therefore, a realistic prevision that this cosmetic category will achieve a compound growth rate (CAGR) of over 13\% between 2012-2017.

Moreover, Asia has gained the title of "world largest sheet mask Innovator" because of the beauty item' ability to offer consumers different skincare benefits, in a convenient manner, and in a short turnaround time. Consequently, consumers are curating their own facial mask routines, according to skin type, life style and product offering.

It has been forecast that, in the future, the trend of this specialized cosmetic product will continue to gain strength driving [1-3,6,7]. The necessary condition will be to maintain the positioning claims with the active ingredients, chosen to match different facial mask formats, delivering maximum efficacy. Additionally, with the customer demand oriented in 2017 to personalize all cosmetic products, it will be necessary to have more connections with educated and smart consumers, giving them answer to the changing life-style values, instead to offer custom formulations only.

It is again to underline that consumers are paying a lot more attention to the product impact on the planet environment, so that climate change calls are more drastic than even before. Thus "premiumization" of the facial mask offering, in term of efficacy and respect of the environment, will play a big part in this year and the year ahead. Sustainability and awareness around environment footprint, in fact, will impact decisions around the type of materials and active ingredients used to make both sheet and packaging which should be reused or recycled (Figure 3). A global innovation with innovative ingredients and smart technologies, therefore, will be necessary to produce masks skin-friendly and environmentally-friendly for the global market necessities and the consumer' requests.

According again to Mintel [2], 53\% of Chinese females agree that the facial masks natural-made are the best first-aid skin care products to be used all the day around, while three in four Chinese consumers use sleeping masks in the evening. It is also interesting to know that in Asia, a growing number of men are experimenting with skincare and cosmetic products which would have typically been used by women. Consequently, it will be necessary to better understand the key differences that lie in consumer usage also. 


\section{TOP OCEAN POLLUTERS}

4 out of 5 top ocean polluters are made of plastic

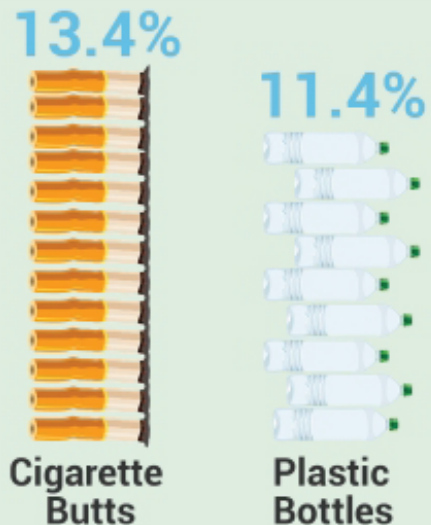

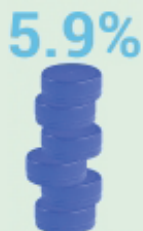

Plastic Bottle Caps

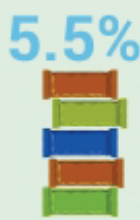

Food Wrappers
Plastic

Bags

Figure 2: The main causes of pollution in land and oceans.

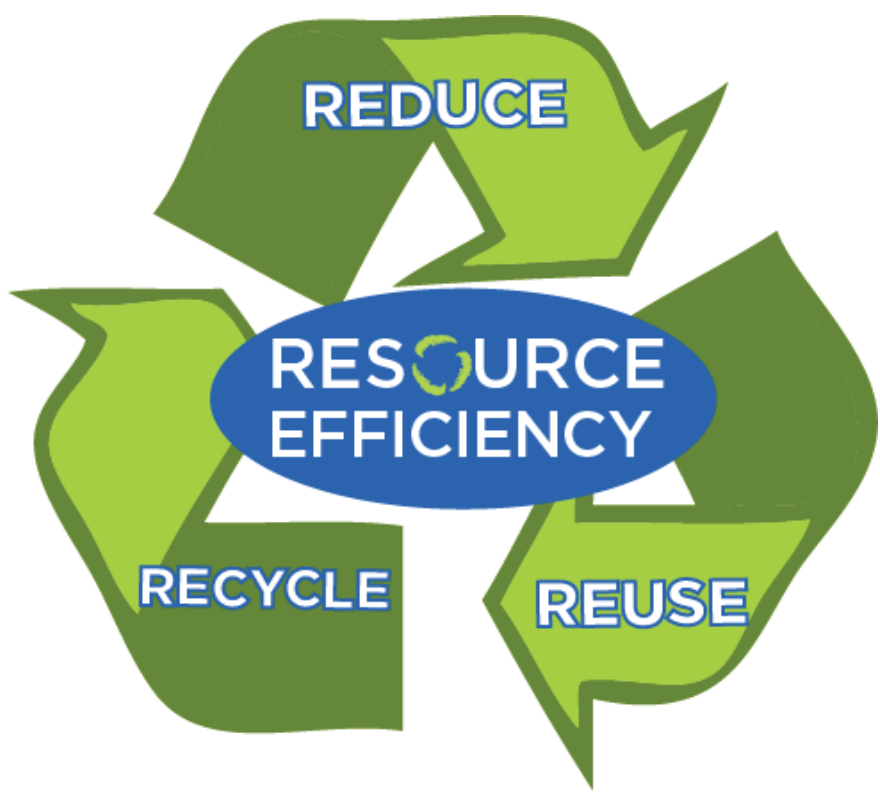

Figure 3: Sustainability of packaging material is another request of consumers who are thinking to the resource efficiency, possible at zero waste.

But what the market in EU, USA, South America and India? As reported previously American and European consumers are increasingly interested in facial skin care mask with a variety of antiaging benefits, looking for natural products to be used: in USA, UK and Italy, for the face; in Spain for eyes and lips [7]. Moreover, 54\% beauty consumers of UK, $74 \%$ of Spain, $44 \%$ of USA, $54 \%$ of Brazil, and $24 \%$ of India are looking for natural products, possibly made by advanced technologies with zero waste.

About the market, the sales of prestige facial skincare masks have grown in USA, UK, Italy and Spain during the 12 months between July 2013 and June $2014[7,8]$. This growth helped to drive $2 \%$ value increases for overall facial skincare sales in both US and UK, and contributed to offset the same segment in Italy and Spain. As an example in 2017 the British women spent $£ 1.15$ billion on facial skin care [2].

However, future projections reveal that Asia will continue to lead both care and mask sales with a global value of $51 \%$ and more.

\section{The Sheet Mask Fabrics}

They are produced using a variety of fabric types. The most common and less expensive mask fabrics are mass manufactured and made from coarse fibers, while the more advanced ones are produced by natural polymers, through sustainable biotechnological processes $[8,9]$. The most gentle and easy-to-use sheet is made of cotton pulp, 
hydro gel and bio-cellulose, all soaked in active ingredients used to pamper and brighten the skin tone, providing to relax and soothe its structure, possibly reducing fine lines and wrinkles [9]. However, due to the presence of water and the many ingredients, used as food from the microorganisms, all these sheets need the use of preservatives, while for the contemporary use of oily compounds different emulsifier compounds are utilized. Finally to increase the consumer acceptance and the aesthetic appearance, fragrance, colors and other chemicals are often added.

In any way, the first component of any sheet mask is the tissue, while the second is represented from different active ingredients.

Tissue is necessary to prolong the contact with the skin and permit the most easy and fast release and penetration of the soaked ingredients, which in turn have to assure the effectiveness of the Mask [9]. The tissue-mask, fitted in the face for about 20/30 minutes, has made with cut opens at the nose, eyes and mouth to permit breathe during its use, also for their itching effects they could cause on skin, because of the presence of preservatives emulsifiers and fragrances.

The selected ingredients, imbibed into the mask and released to the skin are necessary to provide their designed activity, bringing a glowing appearance to all the face.

As previously reported, the major factors driving the global growing of the facial mask market, first of all in Asia-Pacific (APAC), Africa and Latin Americas, include the use of thin natural fibers. Its increasing use is due to the rinsing economic growth, the changing life styles, and rinsing trend of consumer's preference together with their changing buying behavior towards natural beauty products made by innovative technologies [2,6-9]. Consequently, local manufacturers in Africa and APAC, are focusing on new products' development and innovation, in order to develop a local customer base over the years $[2,7]$.

Just to remember, APAC includes countries such as China, India, Japan, South Korea and rest of Asia Pacific, while Africa includes countries such as UAE, South Africa and Middle East, while Latin America comprises of countries such as Brazil and Argentina.

In any way, the sheet face masks have gained popularity among the urban population of nearly every country in the World, because inexpensive, with a texture that feel and behave like paper, and being easy to use with few time consuming. In addition they should have also the capacity to replenish moisture to the skin, regenerating their cells [6-9].

\section{Urbanization and Aging}

About the urbanization problem and according to the WHO Report [10], $54 \%$ of the today's global population is urbanized and by 2050 , $70 \%$ of the world's population will be living in towns and cities. Thus, the protection against the city' air pollution and UV rays are seen as an essential function across all the cosmetic categories, so that $67 \%$ of consumers globally believe that spending less time in the sun and protecting the skin from pollutants by the right product can help them look younger [11,12]. Environmental aggressors such as UV Rays and micro/nano-particulate recovered both outdoor and indoor (Figure 4), in fact, can cause the skin' collagen/elastin breakdown in the skin, accompanied by phenomena of hyper-pigmentation, Inflammation and dehydration. The breakdown of important components of the native Extracellular Matrix (ECM) increase fine lines, wrinkles and age spots provoking the premature aging $[13,14]$. Thus, the prevalent consumer' request is the possibility to buy innovative Face mask formulations, able to neutralize the negative effects of smokes, gas, particulate, heavy metals, ozone, free radicals and UV rays, present especially in the urban areas. This request is based on products having moisturizing and anti-aging activities, being also on-the-go and speed use, possibly at low cost and made by natural ingredients [15].

Among the products, simplicity of using a single product remains the greatest benefits requested from consumers. Moreover, they are looking to a facial sheet mask able not only to maintain a younger appearance for a longer time, but also to provide multiple benefits to supplement or replace their daily skin care. This is due to a population more aged year by year, also if the new generation consumers seem to be more concerned about their look than the older generations, due first of all to their increased living standard and incomes rise [16]. The global anti-aging market, in fact, is projected to grow from US\$ /9.1 billion in 2018 to 36.9 billion in 2022, according to Euromonitor Data [1].

Thus, in 2015, 901 million people on Earth were aged 60 years or older. This number is projected to grow by $56 \%$ through 2050 , eventually totaling 2.1 billion, according to the United Nation Report [17].

However, aging induces various skin related problems or defects such as wrinkles, fine lines, aged spots, etc. Thus, various medical treatments for curing these disorders are being developed to improve the skin appearance, which represents also the same reason for the skin care and cosmetic industry' research investments. It is, therefore, estimated that the sales of dermatological products will surpass US\$ 13 billion by the end of 2018, with the same high CAGR reported for anti-aging cosmetic and over-the-counter products.

In conclusion, the aging population combined with the growing health awareness, the increasing concerns about skin (i.e. irritation, skin allergies, wrinkling, aged spots and acne), and a growing demand for natural face masks, are the factors that are driving the growth of this niche market, dominated from the APAC region, followed from EU and North America, as previously reported.

\section{Environment, Waste and Sustainability}

Today, it is well known that polluted air and water impact negatively on human health, by the toxic contaminants coming from industry and land cultivation [18]. One of the objectives of European policy, in fact, is to reduce the negative impact of the Environment waste, ameliorating the public health and ensuring the most efficient use of resources, particularly the natural ones [19].

Respecting the environment is, therefore, another of the consumers' request worldwide because of the sea and land disasters always more frequent and under the eyes of all. Thus, the customers are paying a lot more attention on the planet and climate changing, looking also for a true zero-waste during all the beauty and personal care supply chain [20]. For this reason in 2019, consumers on the one hand are continuing to focus on well and nice packaged products; on the other hand they will also be drawn to brands that place a wider focus on reducing waste, allowing products/materials to be recovered, regenerated, and reused, rather than disposed of [19].

About waste material it is to remember, for example, that $30 \%$ of the food produced for human consumption globally is lost or wasted along the food supply chain ( $\sim 1.3$ billion tons/year!). Thus, it has been calculated that if food waste was a Country it would be the third largest greenhouse gas emitter after USA and China (Figure 5) [21]. Meanwhile the world's population is predicted to reach 9.1 billion by 2 050 , an increase of $70 \%$ in food availability and the use of waste material is required [21-23]. Thus, reducing loss and waste throughout the food 


\section{HUMAM EXPOSURE TO NP IN PERSPECTIVE}

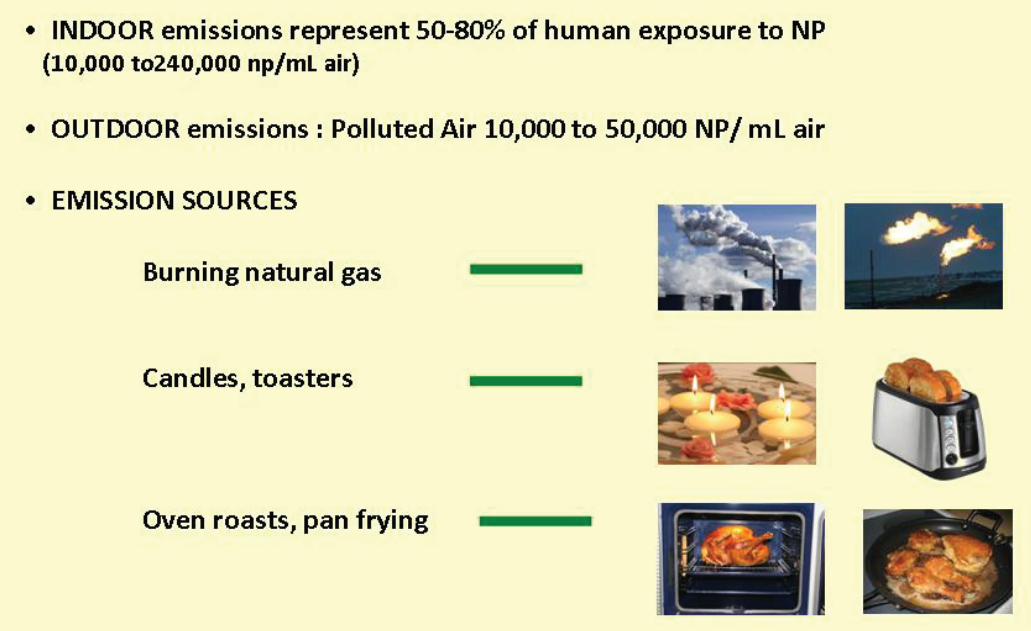

Source: Nohynek, 2011 modified.

Figure 4: Outdoor and Indoor particulate can breakdown the collagen/elastin' skin fibers.

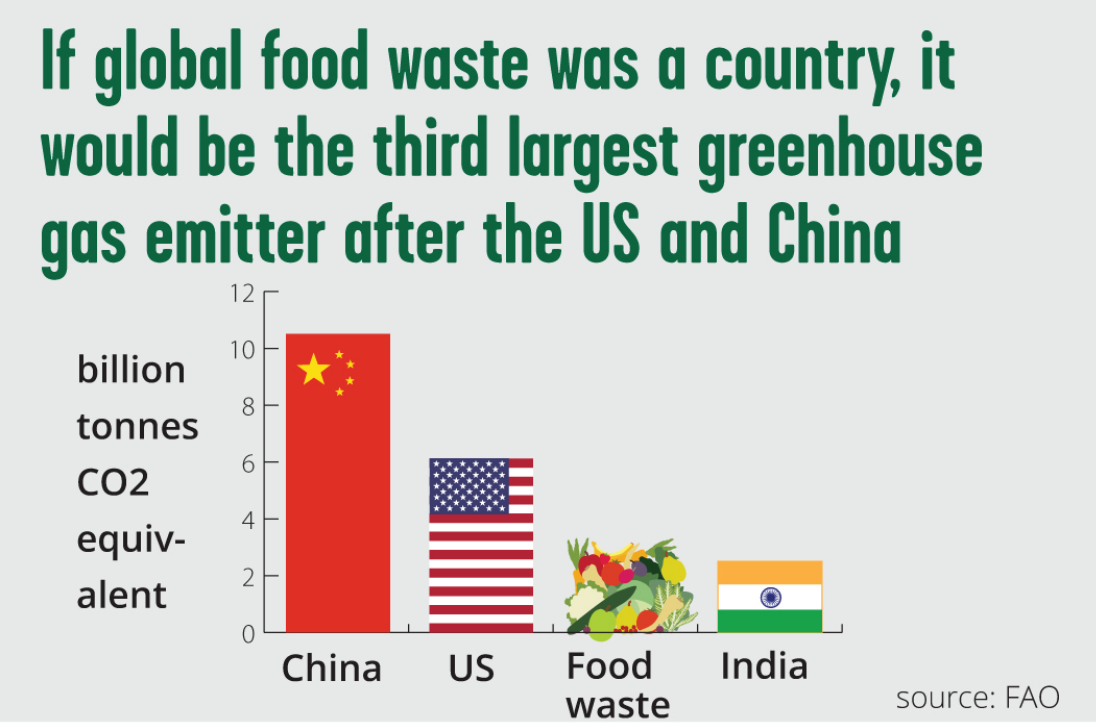

Figure 5: The global food waste in the world.

supply chain and recycle and reuse its active ingredients' content, should be considered an effective solution. This new way of living, will reduce the environmental impacts of agriculture, improving food and nutrition security for consumers who have also to change their mindset on the food use and consume. Additionally, while global plastic waste arrived to 275 million metric tons in 2010 [24], $26 \%$ of total plastic production (311 million tons) is used for packaging purposes with 4,500 billion units of bottles produced yearly. On the contrary and unfortunately, glass, paper and metal has progressively declined (Figure 6) [25].
In this market, the beauty industry produces 120 billion units of packaging per year with a CAGR close to $6 \%$ so that by 2050 it's estimated that there will be 12 billion of plastic in landfills generated by the cosmetic field alone (Figure 7) [26]. Thus, global packaging market for cosmetics industry is expected to be driven by the growth in the end-use segments such as skin care, hair care, baby care, etc. Moreover, the widespread use and the growing variety of cosmetic products for men is expected to boost the growth of this market, as well as the aging population is driving the recent surge in cosmeceuticals with the industrial need for cosmetic bulk packaging market. 


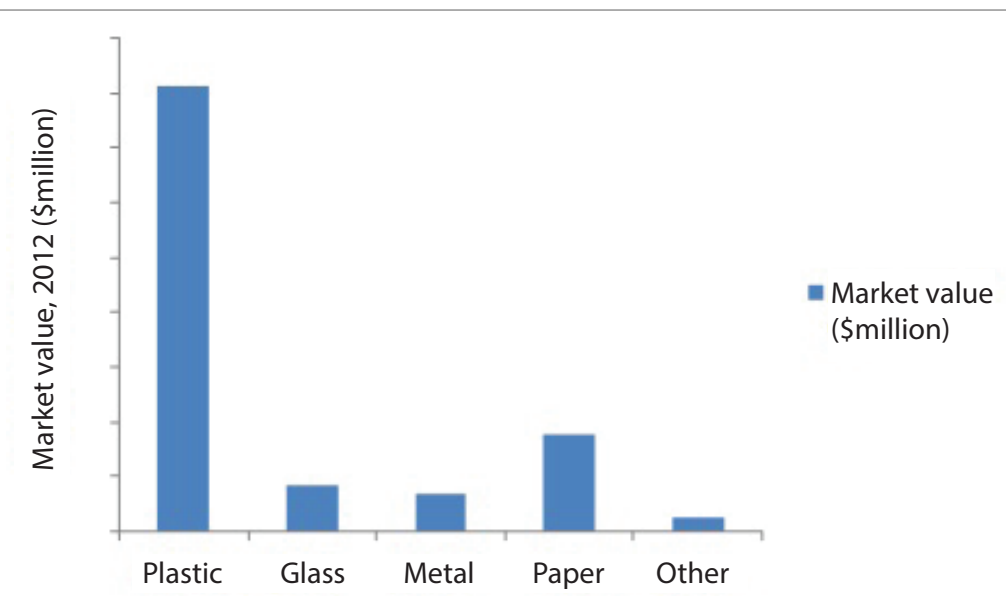

Figure 6: 2012 Market value of Plastic, glass, metal and papers used as packaging material.

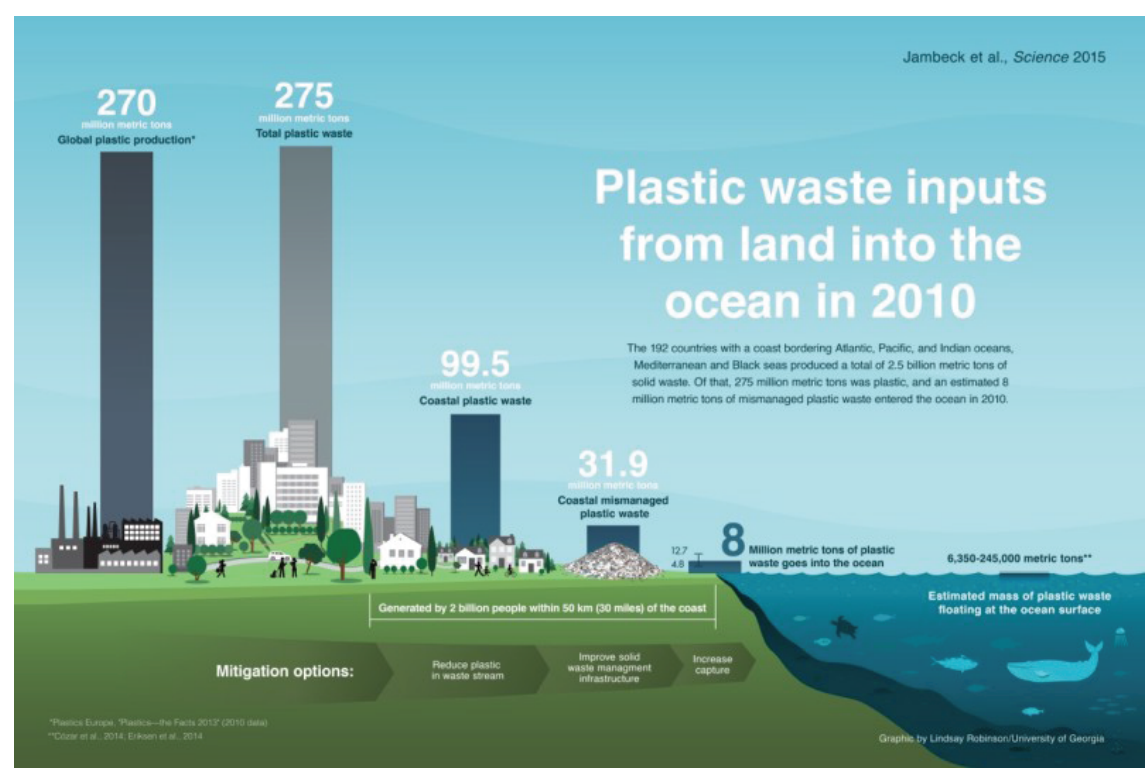

Figure 7: Plastic waste from land into oceans (by the courtesy of Jambeck, et al. [25].

Regarding the regions, China is expected to have the highest growth for the flourishing demand for premium cosmetics and consequently of packaging waste as well as Europe is expected to grow rapidly owing to huge industrial investments into Research and Development.

It is to underlie, however, that since 2017 there has been a revived interest in sustainability focused specifically on packaging and natural raw material obtained from waste. A number of strategies, therefore, are advancing to address the consequential waste, including substituting to alternative materials, investing in the development of bio-based plastics, designing packs to make them easier to process in recycling, and improving recycling and processing of plastic waste. In conclusion, sustainability has become a key motivator for industry and consumers [27]. This is also the aim of the European Research Project Polybioskin [28-30].

\section{Innovation in Facial Sheet Beauty Masks by Smart Carriers}

The Polybioskin project has been organized with the goal to produce industrially: baby/feminine diapers, facial beauty masks and advanced medications.

The materials used are biodegradable and bio-based polymers derived from waste feed stocks, such as polysaccharides (cellulose, starch, chitin, chitosan lignin etc) and biopolyesters (polylactic acid (PLA) and polyhydroxyalkanoates (PHAs) obtained by sustainable technologies [31-34].

Particularly, one of the Facial Beauty Mask studied during the first part of the project, has been made by electrospun fibers which, realized by water-soluble polymers embedded by chitin nanofibrilbiolignin (CN-LG) micro/nanoparticles (NPs), have been bound to active ingredients, previously selected as safe and effective anti-aging agents (unpublished data). The CN-LG complex has been selected as innovative carrier because of its own interesting activity shown recently as antiiflammatory, immunomodulatory, and cicatrizing agent [35-39]. Moreover on the one hand, chitin is completely metabolized from the human and environment enzymes to produce glucosamine, acetyl glucosamine and/or glucose compounds to be used as energy from the cells. 


\section{Chitin and Lignin}

On the other hand the polyphenol lignin is active as antioxidant and antibacterial molecule [38-40]. About chitin, it is interesting to remember its enzymatic degradation process. The enzyme chitotriosidase, in fact, activated by human macrophages, has shown the preference to hydrolyze acetylated units (i.e., chitin) versus no acetylated ones (i.e., chitosan), providing new insight into what kind of compound may be more useful as carrier for the formulation of drugs, cosmeceuticals, and/or food [41]. Moreover, when this polymer is used in its nanodimension (i.e., chitin nanofibril) as delivery carrier, it can entrap/adsorb or load multiple active ingredients, controlling their release and having also the ability to target molecules with specific receptors on the cell surface [36-40]. Thus, chitin and its derivatives exhibit biodegradability and biocompatibility, which can accelerate the development of biological materials, also for its antibacterial and immunomodulatory activity, able to regenerate the skin structured layers, as previously reported.

However, it is to remember that chitin as natural compound found in the outer skeleton of insects, fungi, yeasts, and marine invertebrate including the sea sponges, is the second abundant polysaccharide on the Planet after cellulose [42]. It is an amino-polysaccharide polymer consisting of $\mathrm{N}$-acetyl glucosamine units connected by of Beta-1, 4 -glycoside bonds that, with its high global production, represents a major contribution to pollution in coastal areas [43]. Every year, in fact, more than 1.5 million tons of chitin is available as residues from the fishing industry, while it is estimated that only 10,000 tons are used worldwide for food, cosmetics, and biomedical applications [44]. Thus, the necessity of a major utilization of this natural polymeric biomass by more eco-physiological strategies and processes able to recovery not only chitin, possibly at its nano-dimension but also proteins and calcium carbonate (Figures 8,9) [44]. Moreover, it will be necessary to control its degradation and applications in drug delivery, wound healing, dietary fiber and wastewater treatment as such ,or to complex it with bio-lignin to form micro/nanoparticles, to be used as innovative carriers (Figure 10) [23,29-34].

On the other hand nano-sized lignin, as matrix polymer of wood, is a complex of phenolic heteropolimers which, associated with polyoses in the plant cell wall, is linked to the cellulose elementary fibrils. It is chiefly a low cost by- product of the paper and pulp industry, acting as multifunctional barrier with antibacterial and antioxidant properties [45]. Additionally, lignin is a bio-reasorbent for environmentally harmful metal ions [46], able to protect the skin against the UV radiation and air pollution also [47]. However, the NPs of this polyphenol polymer, being non-toxic and biodegradable are suitable for drug delivery as well as stabilizers of cosmetic and pharmaceutical formulations. This is the reason why nanochitin/nanolignin-based complexes have been used as the main carrier of natural active ingredients. As previously reported [29-36], this smart fibrous carrier on the one hand is able to load and carry the selected ingredients bound on the surface of its fibers. On the other hand the non-woven tissues, made by sugar-like fibers embedded by selected active ingredients, have shown to be effective as active aging mean (data not reported). This is the tissue used to make the innovative Facial, Beauty Mask realized by the Poybioskin EU research project (www.polybiokin.eu). The active ingredients, selected together with the non-woven tissue made by water soluble oligosaccharides into which the ingredients are bound, are therefore used to give effectiveness to this smart Beauty Mask. This innovative active aging cosmeceutical (Figure 11), made of natural ingredients and realized by advanced technologies could be considered a new smart product in line with the actual consumer' requests and dreams. It is not only totally natural and biodegradable with zero waste, but also safe for the skin, lips and eyes, being free from any chemicals, easy to use, and produced at low cost.

\section{Conclusive Remarks}

Currently the Facial Beauty Masks are continuously growing worldwide majorly driven by the demand of anti-aging and dehydrated skin, which strongly influence the consumers' purchase decisions. This cosmetic niche-market is expected to grow significantly because of the rinsing aging population and growing trend in personal beauty enhancer products. This is the reason of the Sheet Face Mask' booming, specifically if made by innovative technologies, natural raw materials, and innovative regenerative formulations [48]. This particular product is, therefore, evolving as a new trend in the cosmetic industry through celebrity endorsements and extensive marketing

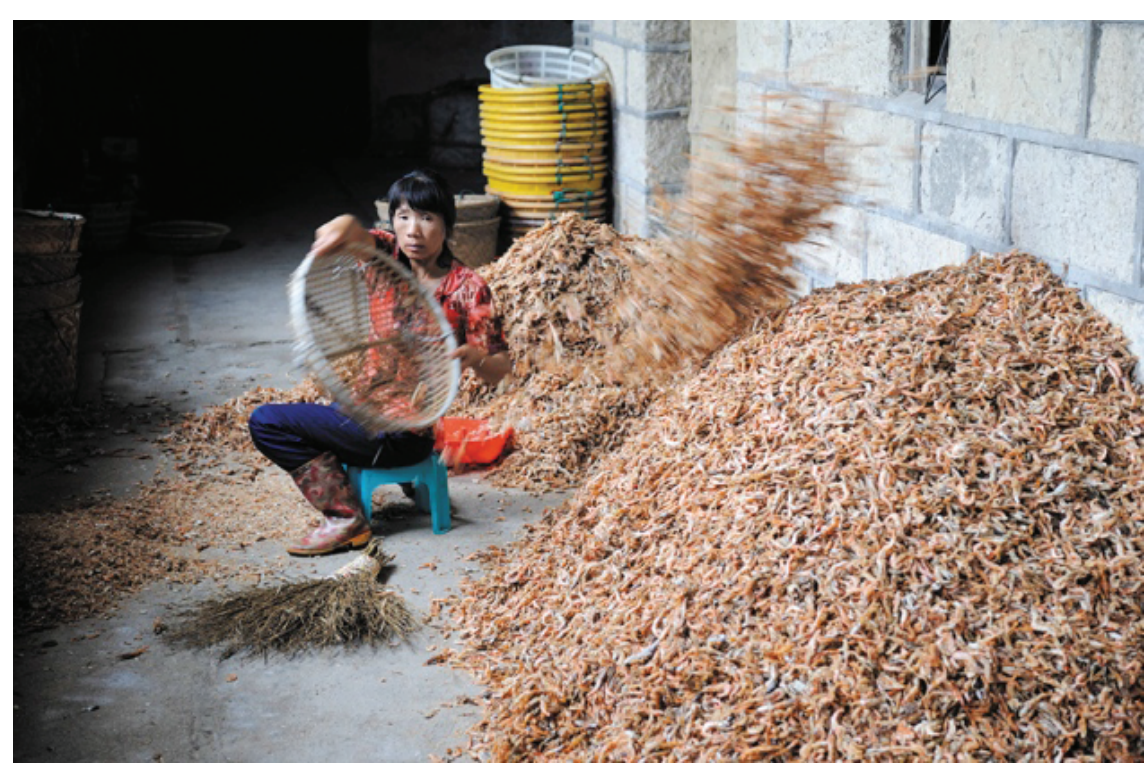

Figure 8: The use of waste from shrimps to produce Chitin (by courtesy of Ning Yan and Xi Chen [44]. 


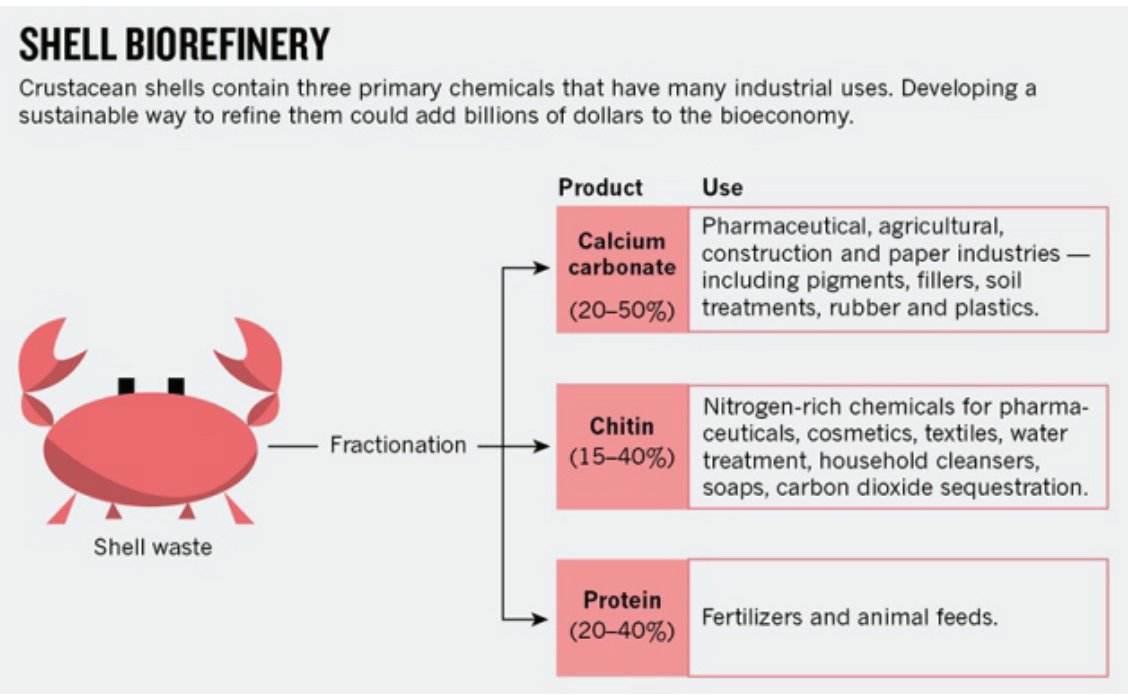

Figure 9: Active ingredients obtainable from Chitin waste by a better extraction process (by courtesy of Ning Yan and XI Chen [44].

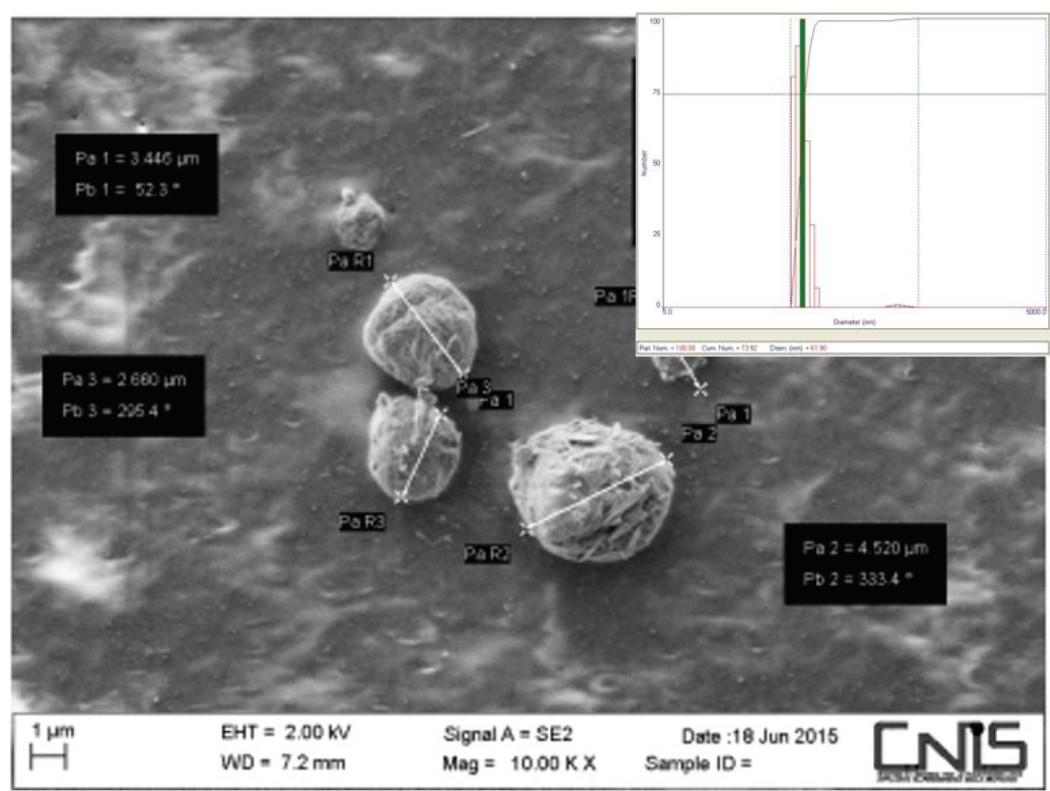

Figure 10: Mean size of Chitin-Lignin micro/nanoparticles at SEM at Zetasizer (source Morganti lab).

campaigns on the social media websites, being considered a new way to maintain a beauty appearance [49]. However, aging cosmetics for elderly moves from the anti-aging claim to active aging, in line with the pursuit of healthier life styles (Figure 12) [50,51]. On the other hand, the new wellness positioning in skin care boosted further adoption levels among young, who are not concerned with anti-aging properties as such, but more with acquiring prevention and health. For all these reasons, the natural sheet masks, such as the chitin-ligninbased reported [32,36,39], could be considered from the consumers innovative and smart cosmeceuticals more beneficial than other beauty products, being active as antipollution also. Naturally their safeness and effectiveness will depend from the adopted formulation, which has to be based on the use of the right carrier, embedded by the right active ingredients, selected for obtaining the designed activity, desired from the consumer. By the experience of our group and the first obtained results, the natural polysaccharides selected for making the non-woven tissues by the electrospinnig technology, seem to be the ideal polymers to produce an innovative active aging Facial Beauty Mask, following the active aging concept [50,51]. Its cosmeceutical effectiveness seems due to the obtained fibers organization/disposition and the active ingredients bound to their structure. On the other hand, the safeness shown is probably due to its natural composition and facility they have to be metabolized by the human and environmental enzymes, without the production of toxic secondary compounds [52].

At this purpose, the latest research from Mintel reveals, for example, that $69 \%$ of Chinese consumers agree that the daily use of cosmeceuticals can prevent skin sensitivity, $74 \%$ underline that it is essential the use of safe and effective ingredients, while $44 \%$ prefer and consider safer formulations with fewer ingredients [15,19,21]. 


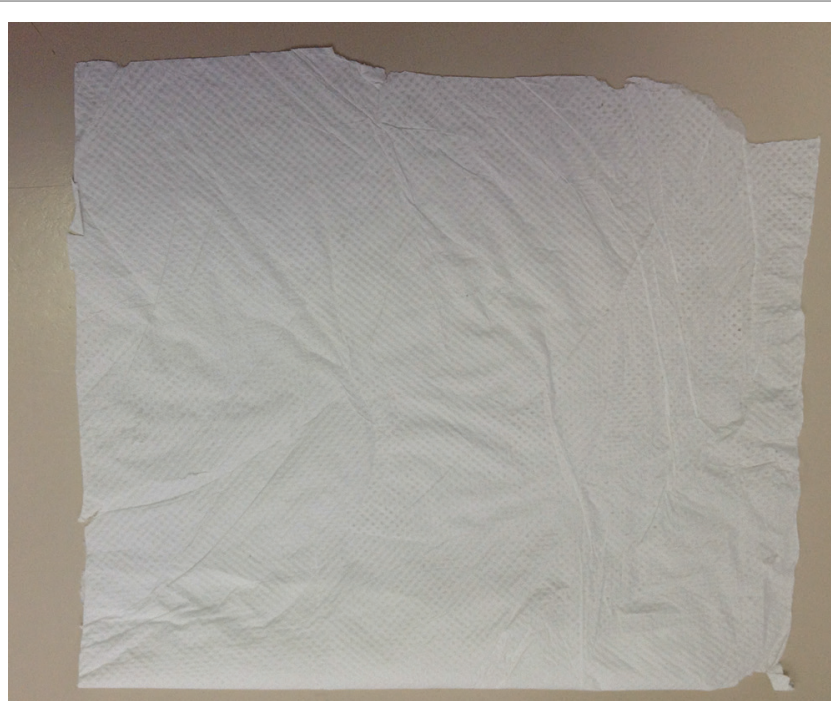

Figure 11: Lab-sample of Active aging masks (source: Morganti lab).

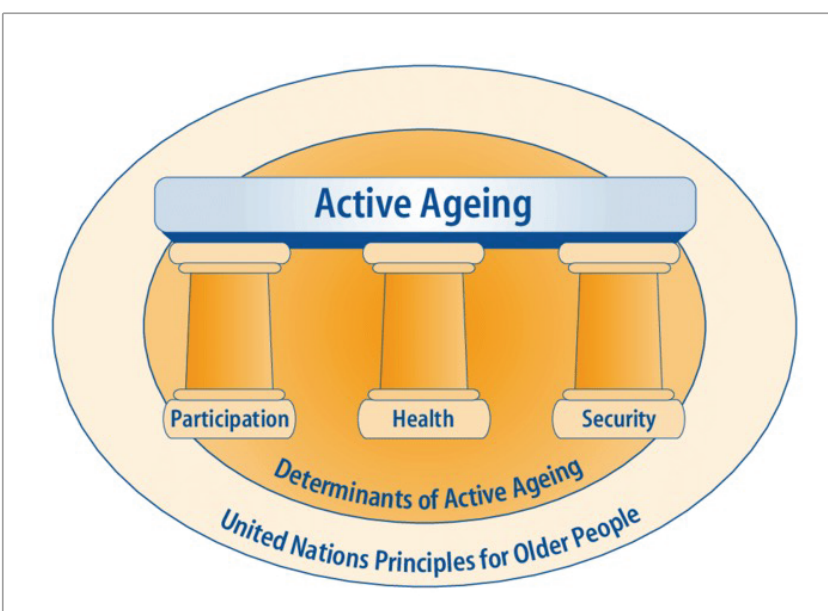

Figure 12: The active aging concept for healthier life styles, according to WHO [50].

The proposed and reported chitin-lignin Face Beauty Mask seems to be in perfect line with the consumer requests within the prestige beauty market that registered a growth sales of this specific cosmetic product by $22.8 \%$ in 2015 and by $25 \%$ for natural brands [53]. Customers, infact, are exploring new products and experimenting new lines in different ways with an increasing interest in facial masks showing an anti-aging and antipollution activity, so that the US prestige Beauty Industries reached US $\$ 17.7$ billion in 2017 with a 6\% increase over 2016 [54]. Moreover, natural-based masks have become a major motivation for consumers in trying new products and aspiring for greater life quality [48].

However, people living in the cities, who are the majority of consumers, are requesting that the cosmetic label has to be transparent on the quality of the product and the obtainable healthy benefits. It is also considered important to underline the importance to use natural and biodegradable ingredients, reporting "what's in" and not only "what's out" from the formulations! [49].
In conclusion the innovative facial masks, with its realization in progress, will be produced by the exclusive use of waste materials, from the formulation' ingredients to the packaging polymers used, all compounds necessary to preserve the natural raw materials for the incoming generations. In addition they will be skin-friendly and environmentally-friendly, totally biodegradable and produced, if possible, at zero-waste [54].

This is our objective and the main goal of the Polybioskin EU Research pro- ject also.

\section{Acknowledgements}

We thank Biobased Industries and Horizon 2020 for the receive fund for the research project Polybioskin which was necessary to, go on with these studies. Moreover, we thank MAVI Sud (Italy) and CIMV (France) for the obtained samples of chitin nanofibrils and Biolignin respectively.

\section{Conflicts of Interest}

The authors declare no conflict of interest.

\section{References}

1. Um S (2018) Skincare trends in 2018. Euromonitor International, UK.

2. Kwek S (2017) 7 Fresh and Innovative Facial Masks Launched in Asia. Singapore, Mintel Group Ltd.

3. Wood L (2018) 2023: Analysis by Type, Type of Packaging, Distribution Channel and Region. Business Wire, Dublin.

4. Wever R, Templeman E (2014) The Social Component of Sustainable packaging.

5. Georgakoudis ED, Tipi NG, Bamford GG (2018) Packaging redesignbenefits for the environment and the community. Int J Sustainable Eng 11: 307-320.

6. Mordor Intelligence (2019) Global Face Mask Market. Gachibowli, Hyderabad.

7. Marshal J (2014) Sales of Facial Masks Outpace Overall Facial Skincare Category Growth in U.S. and Europe. Reports NPD.

8. Reportlinker (2017) Sheet Face Masks Market-Global Industry Analysis: Size, Share, Growth, Trends and Forecast 2016-2024. Reportlinker, NewYork.

9. CISION (2017) Sheet Face Masks Market-Global Industry Analysis, Size, Share, Growth, Trends, and Forecast 2018-2026.

10. WHO (2010) Urbanization and Health. Bull World Health Organ 88: 245.

11. Greinert R, de Vries E, Erdmann F, Espina C, Auvinen A, et al. (2015) European Code against Cancer $4^{\text {th }}$ Edition: Ultraviolet radiation and cancer. Cancer Epidemiol 39: S75-S83.

12. Eide MJ, Weinstock MA (2006) Public health challenges in sun protection. Dermatol Clin 24: 119-124.

13. D'Orazio J, Jarret S, Amaro-Ortiz A, Scott T (2013) UV Radiation and the Skin. Int J Mol Sci 14: 12222-12248.

14. Krutmann J, Bouloc A, Sore G, Bernard BA, Passeron T (2017) The skin aging exposome. J Dematol Sci 85: 152-161.

15. Nielsen Co (2018) The Future of Beauty. Nielsen Report, New York, USA.

16. Mintel (2018) Facial Skincare Market Research Reports-Consumer Behaviour Analysis-Market Trend. Persistent Market Research, Mintel Group Ltd, London ,UK. 
17. UN (2017) World Population Ageing. United Nations Report, NewYork, USA.

18. EC (2013) Soli Contaminants: Impact on Human Health. European Commision, UK.

19. EC (2007) Life and Waste recycling. European Communities, Environment Directorate-General, Bruxelles, Belgium.

20. Mintel (2018) Sub-Zero Waste 2019. Global Beauty and Personal Care Trend. Mintel Group Ltd, London, UK.

21. FAO (2015) Global Initiative on Food Loss and Waste Reduction. Rome, Italy FAO.

22. FAO (2009) How to Feed the World in 2050. Background paper for High Level Expert Forum-How to Fee the World in 2050. FAO, Rome, Italy.

23. Morganti P, Chen Hong-Duo (2017). Knowledge \& Technology to Reduce and Use Food Waste. J Appl Cosmetol 35: 69-79.

24. Kunaver M (2019) Biomass Waste-A Source of Raw Materials. In: Morganti P (Ed) Bionanotechnology to Save the Environment. Plant and Fishery's Bioamass as Alternative to Petrol. MDPI e Book, Basel, Switzerland 18-38.

25. Jambeck JR, Andrady A, Geyer R, Narayan R, Perryman M, et al (2015) Plastic waste inputs from land to ocean. Science 347: 768 771.

26. Ambienta Foundation (2016) The use of packaging is the rise of Consumer. Milan, Italy.

27. Ray S (2019) Global Cosmetic tubes and jars market during the period 2017-2021. Technavio, London, UK.

28. Smithers Pira (2019) Four key trends that will shape the future of packaging to 2028.UK.

29. Morganti P, Coltelli MB, Morganti G (2018) Natural Polymers for a cleaner Environment. Int J Nanotechnol Nanomedicine 3: 1-4

30. Morganti P, Febo P (2017) Problem \& Solution for Biodegrading Baby Diapers. Eurocosmetics 25: 44-46.

31. Morganti P, Coltelli MB, Danti S, Bugnicourt E (2017) The skin goal of EU Polybioskin project. Global Res J Pharm Pharmacol 2: 7-13.

32. Morganti P, Danti S, Coltelli MB (2018) Chitin and Lignin to produce Biocompatible tissues. Res Clin Dermatol 1: 5-11.

33. Morganti $P$, Febo $P$ (2018) Innovative tissue engineering for enlarget market. J Clin Cosmet Dermatol 2.

34. Morganti P (2018) Chitin Nanofibrils: Tuning Fishery's Waste into Goods. J Clin Rev Case Rep 3: 1-3.

35. Zhao D, Yu S, Sun B, Gao S, Guo S, et. al (2018) Biomedical Aplications of Chitosan and its Derivative Nanoparticles. Polymers 10: 462.

36. Morganti P, Coltelli MB (2019) A New Carrier for Advanced Cosmeceuticals. Cosmetics 6: 10 .

37. Morganti P, Del Ciotto P, Stoller M, Chianese A (2016) Antibacterial and Antiinflammatory Green Nanocomposites. Chem Eng Transactions 47: 61-66.
38. Morganti P, Fusco A, Paoletti I, Perfetto B, Del Ciotto P, et al. (2017) Anti-Inflammatory, Immunomodulatory and Tissue Repair Activity on Human Keratinocytes by Green Innovative Nanocomposites. Materials 10: 843 .

39. Morganti P (2019) Bionanotechnology to Save the Environment. Plant and Fishery's Biomass as Alternative to Petrol. MDPI, Basel, Switzerland.

40. De Jong WH, Borm PJ (2008) Drug delivery and nanoparticles: Aplications and hazards. Int J Nanomed 3: 133-149.

41. Eide KB, Norberg AL, Heggset EB, Lindbom AR, Varum KM, et al. (2012) Human Chitotriosidase-Catalyzed Hydrolysis of Chitosan. Biochemistry 51: 487-495.

42. Kaiser K, Brunner R (2008) Major bacterial contribution to the ocean reservoir of detritus organic carbon and nitrogen. Limnol Oceanogr 53: 99-112.

43. Garcia A, Erdocia X, Gonzales Ariols M, Labidi J (2014) Physicochemical Properties and Potential Applications of Lignins from Various Sources. In: F Lu (Ed) Lignin: Structural Analysis, Appications in Biomaterials and Ecolgical Significance. NOVA Publisher, New York, USA 127-160.

44. Yan N, Chen X (2015) Sustainability: Don't waste seafood waste. Nature 524: 155-157.

45. Vinardell MP, Mitjans M (2017) Lignins and their Derivatives with Beneficial Effects on Human Health. Int J Mol Sci 18: 1219.

46. Ge $Y$, Li Z, Kong Q, Wang K (2014) Heavy metal ions retention by bi-functionalized lignin: Synthesis, applications, and adsorption mechanisms. J Ind Eng Chem 20: 4429-4436.

47. Gutierrez-Hernandez JM, Escalante A, Murillo-Vazquez RN, Delgado $\mathrm{E}$, Gonzalez FJ, et al. (2016) Use of Agave tequilana-lignin and zinc oxide Nanoparticles for skin photoprotection. J Photochem Photobiol B Biol 163: 156-161.

48. Face Mask Market (2018) Global Market Study on Face Mask: It Appears to Remain Most Lucrative Market for Face Mask During 2017 to 2026. Persistence Market Reseach, New York, US.

49. Ferreira D (2017) Cosmeceuticals on the Rise in China. Happy Magazine, New York, US.

50. WHO (2002) Active ageing: A Policy Framework .World Health Organization, Madrid, Spain.

51. Liotta G, Canhao H, Cenko F, Cutini R, Vellone E, et. al (2018) Active Ageing in Europe: Adding Healthy Life to Years. Frontier in Medicine 5: 123.

52. Morganti P, Palombo M, Carezzi F, Nunziata ML, Morganti G, et al. (2016) Green Nanotechnology Serving the Bioeconomy: Natural Beauty Masks to Save the Environment. Cosmetics 3: 41.

53. Jensen J (2019) Multi-masking Drives Growth in Prestige Skincare. NPD Group, Inc, Washington, NY, USA.

54. Khan MM, Islam MR (2016) Zero Waste Engineering: A new Era of Sustainable Technology Development. $2^{\text {nd }}$ Edition, Wiley \& Sons, New york, USA. 